\title{
Implementation opportunities of the Moodle Learning Management System in virtual environment The Sloodle Project
}

\author{
Zsolt Kristóf, KÁroly Bodnár and PÉter TAKÁcs
}

Abstract. Using e-learning was firstly appeared in companies' sphere. It should be very useful if learning management systems were applied. Nowadays e-learning is used in different fields and gives useful informations in case of basics and its knowledge.

It is essential to know the arranging technics and applicated handling methods of some supporting learning management systems of e-learning. The Moodle is the bestknown learning management system.

The Second Life is one of the virtual environments which is useful in learningteaching methods that is used in most educational institute all over the world. Sloodle is an open source project which connects the Second Life with Moodle learning management system. Sloodle is a kind of "bridge" in which different kind of activities and registering and provided in both Moodle and Second Life.

In our department, University of Debrecen Health Faculty of Nyíregyháza ILIAS learning management system has operated since February, 2008. In the interest of higher level education we decided to use and made available some courses through Moodle learning management system.

Some tools of Sloodle will be presented in our article. It will be the first study for our research in which we would use the Moodle learning management system, the virtual environment of Second Life and the project of Sloodle itself. Our article will contain the starting details and its statistical confirmation of our Sloodle project. We like to demonstrate that the results of the Sloodle-aided group are significantly better than the results of the control group in the most cases.

Key words and phrases: Sloodle, Moodle, Second Life, ILIAS, virtual environment.

ZDM Subject Classification: B10, Q30, Q70, R50, U60.

Copyright (c) 2011 by University of Debrecen 


$$
\text { "tmcs-kristof" — 2011/11/20 — 19:56 — page } 276 \text { — \#2 }
$$

\section{Introduction}

Our article is about the basic possibilities of Sloodle project and its statistical confirmation which have introduced since September, 2010. As far as we know this is the first and currently active long term project in Hungary which connects a virtual world (Second Life) with a learning managementsystem (Moodle) through the Sloodle tools to experiment the influences of the virtual environment on the education.

We describe the educational environment in the second chapter in a few words. The first e-learning learning management system has been applied in University of Debrecen Health Faculty of Nyíregyháza, in our Health Care Management Department since February, 2008. ILIAS has worked since then. It is used relatively contentedly by students and teachers although most of our teachers just passed the documentum repository phase. We would like to make some of our courses available through Moodle learning management system from September, 2010 .

We briefly introduce the Moodle system in the third chapter.

The fourth chapter provides an introduction to the virtual world of Second Life. The tools of the Sloodle project linking the two above mentioned systems.

In case of using Sloodle, too we should make our education more diversed. On the other hand we could compare the two learning management systems. In the fifth chapter we give an overview about certain Sloodle tools and in the sixth we introduce the details of the project starting with statistical analysis. The partial results of our research are in the last chapter.

\section{Institutional environment}

\subsection{The University}

The University of Debrecen is one of the most famous and well-known higher education institutions with a great historic past in Hungary. With its 15 faculties and 21 doctoral schools it offers the widest choice of research and educational training for its students. The 15 faculties of the University of Debrecen form 3 centres - those of medical sciences, agricultural sciences, and arts and natural sciences. The centres also comprise research institutes, research groups and other auxiliary units aiding education. 


$$
\text { "tmcs-kristof" — 2011/11/20 — 19:56 — page } 277 \text { — \#3 }
$$

The Medical and Health Science centre consist of five faculties. These faculties are the following ones.

- Faculty of Medicine

- Faculty of Dentistry

- Faculty of Health

- Faculty of Public Health

- Faculty of Pharmacy [8]

\subsection{The Faculty}

The Faculty of Health is an educational and organizational unit of the University of Debrecen and it is closely attached to the mother institute.

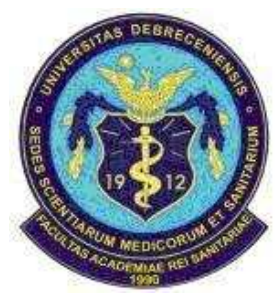

Figure 1. Logo of the Faculty of Health

The teaching started in 1990, at the moment there are nearly two thousand students being prepared for different professions: nurse, ambulance officer, midwife, health visitor, specialist in health insurance, health care manager, health tourism manager, social worker and social worker in health care.

The Faculty of Health co-operates with the Medical and Health Science Centre in order to ensure the scientific and professional background of the education. In addition to nursing almost two thousand inpatients, the Medical and Health Science Centre trains specialists, pharmacists, general practitioners, public health specialists, graduate health care workers, moreover it also offers specialized postgraduate education. The international relations of the Faculty make it possible for the students to continue their studies, do their practice abroad at the co-operating institutes. [9] 


$$
\text { "tmcs-kristof" — 2011/11/20 — 19:56 — page } 278 \text { — \#4 }
$$

\subsection{The Department}

At the Department of Health Informatics we train health managers. The Health Care Management as a basic faculty carries out the educational duties of 3 specializations. These specializations are:

- health information managers,

- specialist in health insurance,

- health tourism manager.

The students study together in the first 3 semesters, where they study mainly some basic knowledge and also the professional corpus of the course. In the fourth semester the training (education) divides into parts, the curriculum of specializations contain mainly profession-specific subject-matter. The training is practice-oriented. The seventh semester is a so called "on the job training" which helps finishing the job training parts of education.

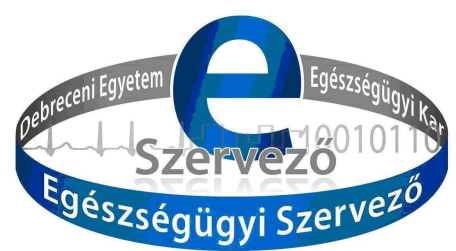

Figure 2. Logo of the division of Health Care Management

The goal of the training is to train health information managers. They should be familiar with the structure of healthcare, the relationship among its institutes and the social security and health insurance. They are also required to be familiar with the financing system of healthcare, its maintenance, code system and data collecting services. They are experienced in the operation of clinical/hospital information systems, their hardware and software components.

Health managers get to know the laws of the health care and human insurances and they fulfil the works of the informatics, the economic and the data processing in these fields. They are able to operate the information systems which are necessary in the area of the health care. [10] 


$$
\text { "tmcs-kristof" — 2011/11/20 — 19:56 — page } 279 \text { — \#5 }
$$

\section{The Moodle Learning Management System}

The word "moodle" was originally an acronym for Modular Object-Oriented Dynamic Learning Environment.

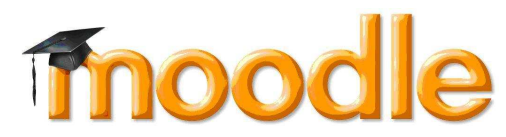

Figure 3. The official logo of the Moodle LMS

Moodle is a course management learning management system (LMS). It was developed to strengthen the interaction between students and to improve learning through the construction of ideas and concrete things for others to experience. This LMS based on the social constructionist philosophy.

Moodle is an open source project. It means among other things that the Moodle course management software is free to download. In addition, the Moodle open source project has a great community of supporters who are instrumental in the continued development of Moodle.

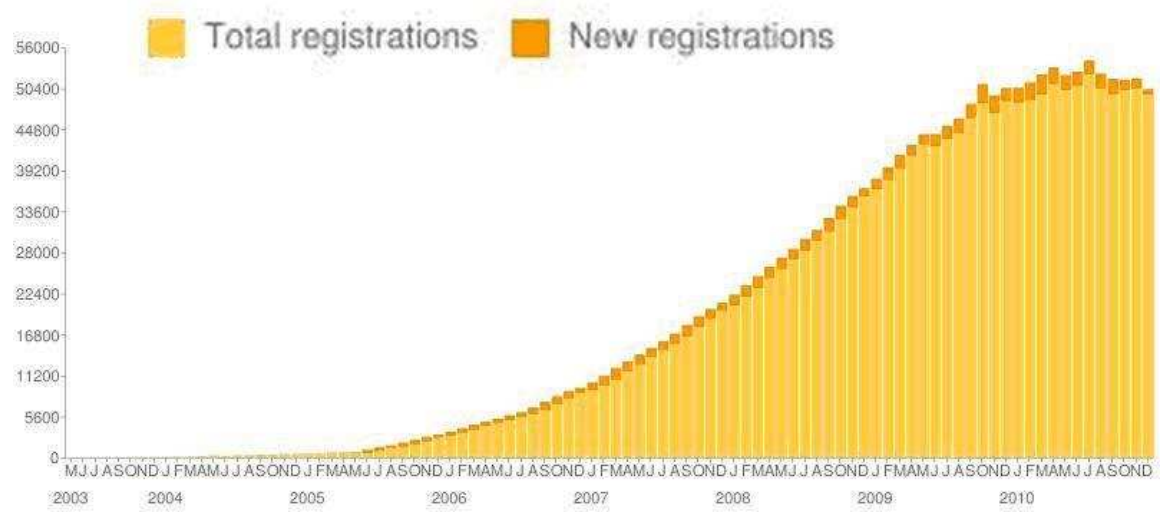

Figure 4. Total known Moodle sites at the end of 2010 [13]

Today, more than 50000 sites in over 210 countries have registered in Moodle. (Figure 4) Moodle is used in public schools, private schools, home schools, universities and corporate training situations. Learners using Moodle range from elementary school students to college scholars. 


$$
\text { "tmcs-kristof" — 2011/11/20 — 19:56 — page } 280 \text { — \#6 }
$$

Here are some examples what kind of activity modules contains The Moodle LMS:

- Assignment: used to assign tasks, can be composed, submitted, and assessed online.

- Chat: allows synchronous communication inside Moodle.

- Choice: facilitators create a question and a number of choices for participants, results are posted for participants to view.

- Glossary: used to create course dictionaries, entries used elsewhere in the course are linked to glossary.

- Lesson: creates a series of linked pages of content with integrated questions.

- Quiz: can be used to create quizzes or surveys with many different types of questions, can provide immediate feedback.

- Resource: primary tool for bringing content into a course, may be plain text, uploaded files, and links to the web.

- Survey: aids teachers in making online classes more effective by offering a variety of surveys.

- Wiki: allows collaborative editing and creation of documents or web pages, see wikipedia.org for an example of the wiki model. [11]

\section{The Second Life, a virtual world platform}

A virtual world is a multi-media environment, which is computer-based and simulated. It is running over the Internet, and designed so that users can interact via their own graphical self representations known as avatars. The Second Life is one of the most popular virtual world platform in use today, with an emphasis on social interaction.

In November 2010, 21.3 million accounts were registered, although there are no reliable figures for actual long-term consistent usage.

Second Life also has a living economy that currently boasts millions of US dollars in monthly transactions via Linden dollar, which can be converted to US dollars at a number of online Linden Dollar exchanges.

Three-dimensional virtual worlds like Second Life can be considered as 3D social networks, where people can collaboratively create and edit objects in the virtual world, besides meeting each other and interacting with existing objects.

Virtual worlds offer novel, intuitive ways to: 


$$
\text { "tmcs-kristof" — 2011/11/20 — 19:56 — page } 281 \text { — \# }
$$

- navigate multi-media content,

- browse information spaces or document repositories in 3D virtual libraries,

- play multi-player games in the virtual world, including educational, health related games,

- buy, sell and advertise virtual and real-life goods and services,

- attend and participate in live events like lectures, conferences, festivals, and concerts.

The potential of such a rich and engaging experience in education must be great. In fact, real and virtual world conferences are being organized to explore and discuss the educational potentials of Second Life. [12]

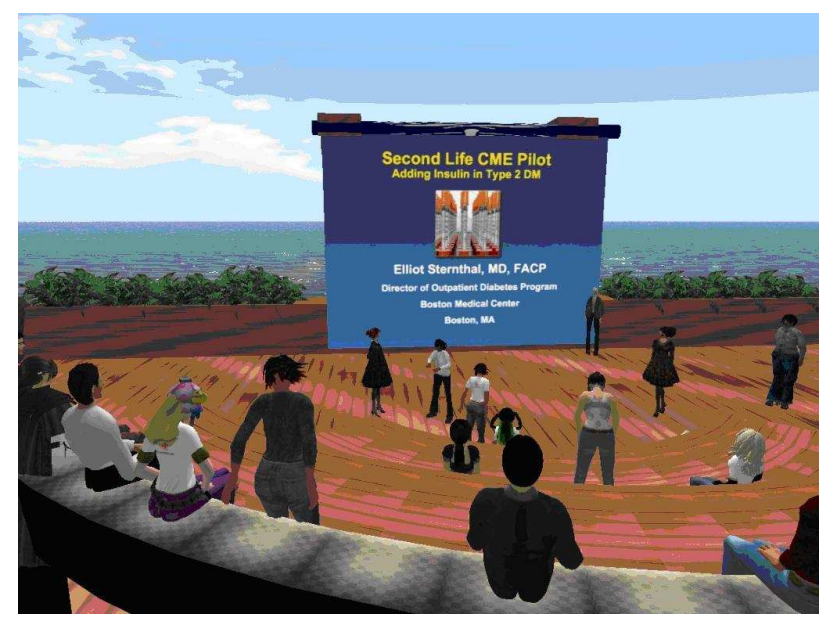

Figure 5. Preparation for a lecture in the Second Life virtual world

\subsection{Educational locations in the Second Life}

Second Life features hundreds of fascinating locations for learning and teaching. Here is a list which includes the well-known places.

\subsubsection{Virtual Campuses}

- Campus: Second Life

- Harvard Law School's Austin Hall 


$$
\text { "tmcs-kristof" — 2011/11/20 — 19:56 — page } 282 \text { — \#8 }
$$

- Hong Kong Polytechnic University, School of Hotel \& Tourism Management

- Ohio University Second Life Campus

- Northern Illinois University, Glidden Campus

- Virtual University of Edinburgh

- Saint Leo University Virtual Campus

\subsubsection{Science and Health}

- Second life Health education (pbwiki) (Navid Tomlinson)

- UC Davis' Virtual Hallucinations (James Linden)

- Heart Murmur Sim

- The U.S. Centers for Disease Control and Prevention (CDC) in Second Life

- Second Health - Imperial College, London

- Second Life Medical Library 2.0/Consumer Health Library/HealthInfo Island

- Genome (Biology, Genetics)

\section{The Sloodle project}

The Sloodle (Simulation Linked Object Oriented Dynamic Learning Environment) is an open source project which integrates the virtual environment of Second Life with the Moodle learning-management system. Sloodle provides lot of tools for supporting learning and teaching to the virtual world which are fully integrated with a tested web-based learning management system used by hundreds of thousands of educators and students worldwide. It is ultimately up to tutors and students to decide how tools should be used in class. The following are a list of tools which can be key features in the teaching-learning methods. [14]

\subsection{WebIntercom}

The WebIntercom - which used to be known as the "chat logger" - tool can connect the public text chat in Second Life to a specified chatroom in a Moodle LMS. This application allows that a chat can be shared between Second Life and Moodle, which is very useful if someone do not have access to Second Life. A good example of this is the Teen Grid of the Second Life. In the Teen Grid some users may not have clearance. Although an authorised user could setup a WebIntercom 


$$
\text { "tmcs-kristof" — 2011/11/20 — 19:56 — page } 283 \text { — \#9 }
$$

while others chat from Moodle. The Moodle chat is also logged, which is useful for keeping a record of in-world chat sessions.

\subsection{Registration booth}

The Registration booth solves the identity management for Second Life and Moodle. With the help of this tool it is possible to link the students' avatars to their Moodle user accounts.

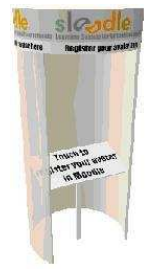

Figure 6. The registration booth

After the Registration booth rezzed, it can be use by clicking the "Touch to register your avatar in Moodle" panel. First, the tool will check if the avatar is already registered in the associated Moodle site. If the avatar totally registered, and is linked to the appropriate Moodle account, then there is no other thing to do for the registration. Otherwise, the Booth will create a new entry for the avatar in the Moodle database, then display a URL in the virtual world. The "Go To Page" button will load the URL, and a web-browser will appear, showing the Moodle site to register.

\subsection{Quiz chair}

The Quiz chair tool allows users to attempt a Moodle quiz from with in Second Life, and receive instant visual feedback. Once the Sloodle based website connected to the Quiz chair the tool will download the specified multiple choice quizes from the site, and send to the avatars of the students. By answering the questions, the chair will actually go up, or down, depending on their answers.

The Quiz chair automatically stores quiz results in the Moodle database, and in the Moodle gradebook.

After the 1.0 Sloodle Set version the tool has some new features. It now listens to numerical and short answers through local chat and multiple choice and 


$$
\text { "tmcs-kristof" — 2011/11/20 — 19:56 — page } 284 \text { — \#10 }
$$

true-false through the dialog menus. The Quiz chair has limited memory, so we have to try to keep questions, answers and feedback fairly short.

\subsection{Choice tool}

This application allows the students to vote and see results in Second Life as well as in Moodle. With this tool the teacher can bring Moodle Choice activities into Second Life. The Choice activity module provides a means to run polls, elections or general information gathering from participants in a course. Therefore, after a poll has been set up via the Choice activity in Moodle, and connect it to a Sloodle Choice object in Second Life the Poll graphically represented in the virtual world.

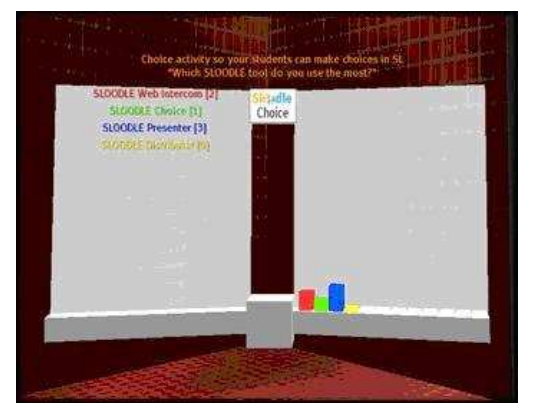

Figure 7. An active Sloodle Choice tool

Each Choice in the Choice activity will be displayed as colored text. The main question will be displayed as text as well at the top of the Choice tool in Second Life. To submit their choice, a student simply needs to click on the colored bar matching the color of the text of their choice preference.

\subsection{Presenter}

The Sloodle Presenter is a tool for creating presentations in Second Life. Very important feature is the Presenter avoids the requirement to upload images into Second Life and allows presentations to combine images, web-pages and videos by streaming the presentation content into Second Life.

The Presenter uses the parcel media settings, so it must be owned by the land owner. If it is not possible it has to be deeded to the land owning group. Presentations can be viewed in Second Life or in Moodle. The Presenter can be 


$$
\text { "tmcs-kristof" — 2011/11/20 — 19:56 — page 285 — \#11 }
$$

set to allow any avatar to control the presentation using the forward and back buttons.

Currently there have been several reported problems with the Presenter on Second Life Viewer 2.

\subsection{Sloodle Awards System}

The Sloodle Awards System enables teachers to award students with points through an interactive scoreboard system. After the configuration the Sloodle Awards System Scoreboard will display the names of all students enrolled in a specified course. The teacher can give points to a student by clicking on the students name. Each scoreboard is also connected to a special "Sloodle Awards" Moodle assignment. This tool gives teachers the ability to grade students while in Second Life through the Sloodle Awards System Scoreboard.

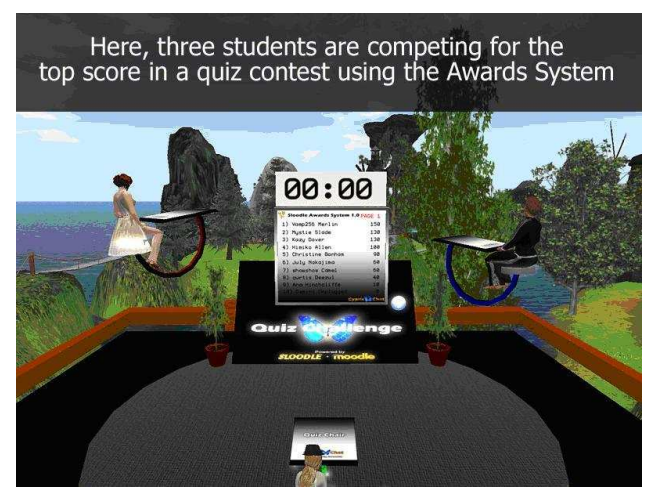

Figure 8. Three students are competing using the Awards System

The Sloodle Awards System operates like a bank structure. Points are like as "Credits" and when subtracted, are like as "Debits". Students final total point is their Sloodle Awards System balance.

Operating in this way, a teacher can easily view the history of all transactions towards a students' total by visiting the Sloodle Awards Activity within Moodle. To add points, a teacher simply clicks on the name of a student. A menu then appears and the students total can be modified. Once the correct modification is made, the teachers presses "Save" and the transaction is processed) then the scoreboard is updated. 


$$
\text { "tmcs-kristof" — 2011/11/20 — 19:56 — page } 286 \text { — \#12 }
$$

\subsection{The Sloodle Game Show}

The Sloodle Game Show is an open source game that gets connected to a Moodle website using the Sloodle platform. After the connection made a teacher can be a game show host, and the students will be the contestants.

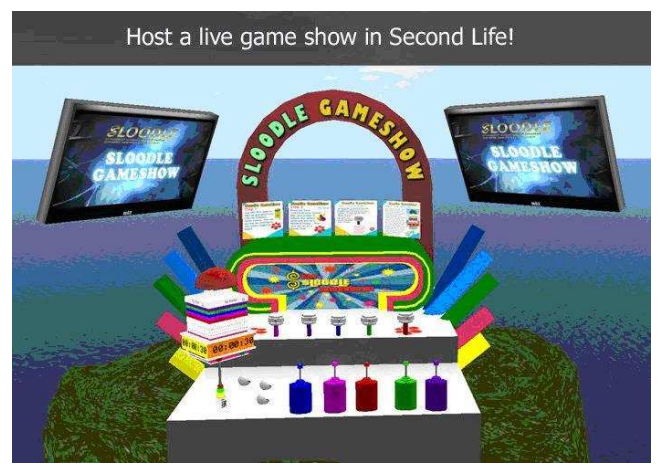

Figure 9. A Sloodle Game Show waiting for its contestants

The tool includes a rezzer, game chairs with auto-color coding, audience landmarks, game buzzer, game timer, and a scoreboard. Students sit on game chairs, which automatically connect with Moodle, detect the group the student is in, and then move the student to the audience where the rest of their team members are sitting. If the game host like to bring the students up to the front all he have to do is click on the specified chair. Then the host asks a question and students click the buzzer to indicate that they would like to answer. The host gives points then the scores of the teams will be updated on the Scoreboard, and on a specified Moodle website.

\section{Project starting and statistical confirmation}

We started the study of the above-mentioned learning management systems in our faculty at 2008. There are some successful projects behind us. We present some of our own Sloodle-related results in this section.

The first part of the chapter lists the subjects which were examined. The second part contains the details of the statistical analysis.

The main goal of our research is to explore how the electronic learning methods can support the classic learning processes. The outcomes we present in this 


$$
\text { "tmcs-kristof" — 2011/11/20 — 19:56 — page } 287 \text { — \#13 }
$$

paper comparing the results of the Sloodle-aided group and the control group. We collate the preliminary knowledge of the examined groups in the chapter 6.1 and chapter 6.2. Chapter 7. contains the basic comparison of the results of the classic and the Sloddle-aided learning processes.

\subsection{Details of project starting}

In case of teaching Planning and managing of information systems II. and Database management II. have been introduced with supplementary Sloodle tools since September, 2010.

Planning and managing of information systems II. is a theoretical and practical subject where students get the knowledge of Martin-model. They have to make different kind of documents and they also have to work out a complete project and the end of the term.

Database management II. is a practical subject in which students can examine those theoretical knowledge of Database management I. in practical fields. Our students mainly get assignments which are solved by Microsoft Access and OpenOffice.org Base.

Our students were selected randomly for the project in both subjects. Those who was chosen for this project got a kind of education where Sloodle tools were applied. The others took part in ordinary training. They were the created control group.

Table 1. Students taking part of different subjects

\begin{tabular}{|c|c|c|}
\hline & $\begin{array}{c}\text { Sloodle aided } \\
\text { students' numbers }\end{array}$ & $\begin{array}{c}\text { Numbers of students } \\
\text { in ordinary training }\end{array}$ \\
\hline Database management II. & 16 & 22 \\
\hline $\begin{array}{c}\text { Planning and managing } \\
\text { of information systems II. }\end{array}$ & 17 & 20 \\
\hline
\end{tabular}

The sample details are in the Table 1.

We examined whether there are significant differences between pre-Sloodle results of the Sloodle-aided group and control group. We would have proved that the earlier educational results did not influence the selection. 


$$
\text { "tmcs-kristof" — 2011/11/20 — 19:56 — page } 288 \text { — \#14 }
$$

\subsection{Statistical analysis}

During the analysis we got data from Neptun and Moodle systems. We did the survey applying with SPSS statistical software with 0.95 confidence level.

6.2.1. Examining the results of those students who attended Database management I. and II. subject

The mean of marks of the Database management I. which is directly connected to the Database management II. was 2.63 with 0.82 deviation. Distribution of the marks of the Database management I. did not seem normal (KolmogorovSmirnov normality test $p=0.00$; Shapiro-Wilk normality test $p=0.00$ ). If we use the Mann-Whitney test, there would not be differences between the two samples as well $(p=0.374)$.

38 people attended the Database management II. subject in the first term of 2010/2011. From 38 students 16 take part in the Sloodle project.

Corrected credit index mean was 2.98 with 0.86 deviation. Distribution of data seem normal (Kolmogorov-Smirnov normality test $p=0.20$; Shapiro-Wilk normality test $p=0.65)$.

We checked the equivalency of the corrected credit index of the two above mentioned groups with two sample T-test and its appropriate Mann-Whitney test, too. The homogenity of variance which is a prerequisite of the two sample T-test was fulfilled (Levene's test $p=0.717$ ). The two sample T-test shows equivalent the expected values of the corrected credit index of the two groups $(p=0.138)$. The same equivalence can be seen during the Mann-Whitney test $(p=0.234)$.

The mean of the summarized corrected credit indexes of the Database management II. was 3.09 with 0.69 deviation. Distribution of data seem normal (Kolmogorov-Smirnov normality test $p=0.153$; Shapiro-Wilk normality test $p=0.122)$.

We did the same examination in case of summarized corrected credit index as we did in case of corrected credit index. The homogenity of variance was fulfilled (Levene's test $p=0.504$ ). The two sample T-test shows equivalent the expected values of the corrected credit index of the two groups $(p=0.130)$. The same equivalence can be seen during the Mann-Whitney test $(p=0.201)$.

Summarizing we should say that the students of the Sloodle and non-Sloodle groups of Database management I. and II. cannot be divided if we see their earlier marks. The two groups show similar learning abilities. 


$$
\text { "tmcs-kristof" — 2011/11/20 — 19:56 — page } 289 \text { — \#15 }
$$

During the following analysis we should reject the possibility that only those students took part in the Sloodle-project who are significantly better or significantly worse than the average.

6.2.2. Examining the results of those students who attended Planning and managing of information systems I. and II. subject

The mean of marks of the Planning and managing of information systems I. which is directly connected to the Planning and managing of information systems II. was 3.64 with 0.99 deviation. Distribution of the marks of the Planning and managing of information systems I. did not seem normal (Kolmogorov-Smirnov normality test $p=0.001$; Shapiro-Wilk normality test $p=0.001$ ). If we use the Mann-Whitney test, there would not be differences between the two samples as well $(p=0.731)$.

37 people attended the Planning and managing of information systems II. subject in the first term of 2010/2011. From 37 students 17 take part in the Sloodle project. Corrected credit index mean was 2.82 with 0.89 deviation. In this case distribution of data did not seem normal (Kolmogorov-Smirnov normality test $p=0.018$; Shapiro-Wilk normality test $p=0.009$ ).

We checked the equivalency of the corrected credit index of the two above mentioned groups with Mann-Whitney test. The test shows equivalent the expected values of the corrected credit index of the two groups $(p=0.175)$.

The mean of the summarized corrected credit indexes of the Planning and managing of information systems II. was 3.09 with 0.65 deviation. Distribution of data seem normal (Kolmogorov-Smirnov normality test $p=0.200$; Shapiro-Wilk normality test $p=0.800$ ).

We did the same examination in case of summarized corrected credit index as we did in case of corrected credit index. The homogenity of variance was fulfilled (Levene's test $p=0.105$ ). The two sample T-test shows equivalent the expected values of the corrected credit index of the two groups $(p=0.177)$. The same equivalence can be seen during the Mann-Whitney test $(p=0.175)$.

Summarizing we should say that the students of the Sloodle and non-Sloodle groups of Planning and managing of information systems I. and II. cannot be divided if we see their earlier marks. The two groups show similar learning abilities. During the following analysis we should reject the possibility that only those students took part in the Sloodle-project who are significantly better or significantly worse than the average. 


$$
\text { "tmcs-kristof" — 2011/11/20 — 19:56 — page } 290 \text { — \#16 }
$$

\section{The partial results of our research}

The following calculations compare the results of the classic and the Sloddleaided learning processes. In the classic learning process we use lectures, practices, verbal communication, projector, projected presentations, and so on.

In the Sloodle-aided learning processes we use Webintercom, Registration Booth, Quiz Chair, Choice Tool, Vending Machine and the Metaglossary besides the above-mentioned methods.

We compared the results of the two groups of the Database management II. and Planning and managing of information systems II. subjects. We have evaluated our three tests and three conceptualization tasks. The following computational statistical results were obtained.

The tests indicate $\mathrm{T}$ (T1, T2, T3) and conceptualization tasks indicate F (F1, F2, F3).

In the Database management II. subject the T1 test and the F1 conceptualization task contains such topics as Functional dependencies, Keys of relations, Rules about functional dependencies and Closure of attributes. T2 and F2 are based on the 12 rules of Codd and elemental practicing of Microsoft Access. T3 and F3 are include some more difficult practical aspects of Microsoft Access and mainly the methods of Database normalization.

In the Planning and managing of information systems II. subject the T1 test and the F1 conceptualization task contains such topics as General informations about the Martin-model, Graphic illustration and explanation of the Martinmodel documents and the Companies function (CF). T2 and F2 are based on the theoretical views of the Organization diagram (ORG), the Functional decomposition (FD), the Entity-Relation diagram (ERD) and the External diagram (EXD) as a document in the Martin-model. T3 and F3 are include the matrixes in the Martin-model. At this part of the subject the students have to make the Create/use matrix, the Business area matrix and the RAEW matrix in practical way.

In the first step we were tested for normality with Kolmogorov-Smirnov test (KS) and Shapiro-Wilk test (SW). Thereafter we compared the results between the two groups with Levene's test for equality of variances, T-test for equality of means and Mann-Whitney test.

The first group is the Sloodle-aided group (1) and the second group is the traditional group (2).

The results are summarized in Table 2 . and 3. 


$$
\text { "tmcs-kristof" — 2011/11/20 — 19:56 — page } 291 \text { — \#17 }
$$

Implementation opportunities of the Moodle Learning Management System ... 291

Table 2. Partial results of our research of the Database management II.

\begin{tabular}{|l|l|l|l|l|l|l|}
\hline & T1 & T2 & T3 & F1 & F2 & F3 \\
\hline$n=38$ & & & & & & \\
\hline & & & & & & \\
\hline Kolmogorov-Smirnov test $(p)$ & 0.200 & 0.036 & 0.200 & 0.018 & 0.200 & 0.024 \\
\hline Shapiro-Wilk test $(p)$ & 0.293 & 0.045 & 0.134 & 0.048 & 0.182 & 0.010 \\
\hline mean of the group 1 & 12.00 & 16.19 & 14.88 & 14.88 & 14.69 & 14.56 \\
\hline std. deviation & 4.21 & 2.26 & 3.46 & 2.06 & 3.59 & 4.99 \\
\hline mean of the group 2 & 9.45 & 14.95 & 13.45 & 11.73 & 11.05 & 13.00 \\
\hline std. deviation & 3.10 & 2.65 & 2.86 & 3.15 & 3.09 & 3.56 \\
\hline T-test & $\mathbf{0 . 0 3 8}$ & 0.141 & $\mathbf{0 . 1 7 5}$ & 0.001 & $\mathbf{0 . 0 0 2}$ & 0.267 \\
\hline Mann-Whitney test & 0.033 & $\mathbf{0 . 1 5 3}$ & 0.137 & $\mathbf{0 . 0 0 3}$ & 0.003 & $\mathbf{0 . 1 0 8}$ \\
\hline
\end{tabular}

Table 3. Partial results of our research of the Planning and managing of information systems II.

\begin{tabular}{|l|l|l|l|l|l|l|}
\hline & T1 & T2 & T3 & F1 & F2 & F3 \\
\hline$n=37$ & & & & & & \\
\hline & & & & & & \\
\hline Kolmogorov-Smirnov test $(p)$ & 0.019 & 0.000 & 0.200 & 0.200 & 0.000 & 0.020 \\
\hline Shapiro-Wilk test $(p)$ & 0.143 & 0.001 & 0.511 & 0.622 & 0.015 & 0.038 \\
\hline mean of the group 1 & 14.24 & 13.35 & 14.00 & 15.24 & 13.06 & 14.65 \\
\hline std. deviation & 2.49 & 2.55 & 4.32 & 2.95 & 2.49 & 3.22 \\
\hline mean of the group 2 & 12.25 & 12.50 & 11.00 & 13.00 & 10.78 & 12.10 \\
\hline std. deviation & 3.11 & 3.43 & 2.97 & 2.90 & 3.42 & 4.10 \\
\hline T-test & $\mathbf{0 . 0 4 1}$ & 0.403 & $\mathbf{0 . 0 1 8}$ & $\mathbf{0 . 0 2 6}$ & 0.032 & 0.046 \\
\hline Mann-Whitney test & 0.028 & $\mathbf{0 . 5 9 8}$ & 0.013 & 0.045 & $\mathbf{0 . 0 4 9}$ & $\mathbf{0 . 0 4 5}$ \\
\hline
\end{tabular}

In summary we can say that the Sloodle-aided group performed significantly better.

The T1, T2 and T3 tests and the F1, F2, F3 conceptualization tasks and theirs sequences reflect some of the educational methods of the two subject. The theoretical lectures and informations are presented before the practical studies in both subjects. This means that the $\mathrm{T} 1$ and the F1 are strongly theoretical based, the $\mathrm{T} 2$ and the F2 contains almost equal theoretical and practical exercises and the T3 and the F3 are strongly practical based.

In the case of the Database management II. subject the results of the Sloodleaided group were significantly better in three surveys (T1, F1, F2). 


$$
\text { "tmcs-kristof" — 2011/11/20 — 19:56 — page } 292 \text { — \#18 }
$$

In the case of the Planning and managing of information systems II. subject the results of the Sloodle-aided group were significantly better in five surveys ( $\mathrm{T} 1$, T3, F1, F2, F3).

Based on the above mentioned facts we conclude that using of the Sloodle tools is excellently applicable to support of the theoretical education. However it seems that the usage of the examined Sloodle tools does not cause significant changes in the sphere of the practical studies. Therefore at this phase of the research we recommend the Sloodle tools to the theoretical educators rather than the practical ones.

In our opinion, the analysis demonstrate the legitimacy of virtual environment aided e-learning systems in education again.

Through the first semester of the $2010 / 2011$ we have not completed the full research yet. Therefore we only have partial results.

\section{Summary}

We tried to explain some of the Sloodle tools in our article. We should not undertake the totality of the Sloodle tools. On one hand the opportunities of the tools can be limited only by imagination. On the other hand the development is widespread and the Sloodle tools change relatively rapidly. At the same time the above mentioned possibilities show the way which was set by the Sloodle tools itself. Educational methods which are supported by Sloodle have been applied among some courses of our department since September, 2010. We would like to report about our experiences in the near future.

\section{References}

[1] Mobile Learning and Lifelong Knowledge Acquisition, in: Mobile Studies: Paradigms and Perspectives, Communications in the 21st century. The Mobile Information Society, (Kristof Nyiri, ed.), Passagen Verlag, Vienna, 2007.

[2] Researching Learning in Virtual Worlds, (Anna Peachey, Julia Gillen, Daniel Livingstone, Sarah Smith-Robbins, eds.), Springer, 2010.

[3] Games-Based Learning Advancements for Multi-Sensory Human Computer Interfaces, Information Science Reference, (Thomas Connolly, Mark Stansfield, Liz Boyle, eds.), 2009.

[4] D. Livingstone and J. Kemp, Integrating Web-Based and 3D Learning Environments: Second Life meets Moodle, in: Upgrade, Vol. IX, no. 3, 2008. 


$$
\text { "tmcs-kristof" — 2011/11/20 — 19:56 — page } 293 \text { — \#19 }
$$

[5] M. Marton and P. Marton, 2008, http://elearning.ttmk.nyme.hu/file.php/1/Segedletek/tanari_kezikonyv.pdf.

[6] Online Learning in Virtual Environments with SLOODLE, Final Project Report, (Daniel Livingstone, ed.), Eduserv, 2009.

[7] M. N. K. Boulos, L. Hetherington and S. Wheeler, Second Life: an overview of the potential of 3-D virtual worlds in medical and health education, Health Information \& Libraries Journal, 2007.

[8] Site of the University of Debrecen, http://www. unideb.hu.

[9] Site of the University of Debrecen, Faculty of Health, http://www.de-efk.hu.

[10] Site of the University of Debrecen, Faculty of Health, Department of Health Informatics, http://www.de-efk.hu/index.php/egeszseguegyi-szervez-alapszak.

[11] Moodle community site, http://www.moodle.org.

[12] Official site of the Second Life virtual world, http://secondlife.com.

[13] Statistical site of the Moodle, http://moodle.org/stats/.

[14] Official site of the Sloodle tools, http://www.sloodle.org.

ZSOLT KRISTÓF KÁROLY BODNÁR and PÉTER TAKÁCS

UNIVERSITY OF DEBRECEN

HEALTH FACULTY OF NYÍREGYHÁZA

DEPARTMENT OF HEALTH INFORMATICS

NYÍREGYHÁZA

HUNGARY

E-mail: kristofzs@de-efk.hu

E-mail: bcharles@de-efk.hu

E-mail: vtp@de-efk.hu

(Received January, 2011) 